\title{
The Directions of the Development of the Kalmyk Nomadic Economy in the late XIX - Early XX Centuries
}

\author{
Aleksandr Narmaevich Komandzhaev, Evgeny Aleksandrovich Komandzhaev \\ and Mergen Sanalovich Goryaev
}

Kalmyk State University, Russian Federation, 358000, Elista, Pushkin St., 11

DOI: http://dx.doi.org/10.13005/bbra/1968

(Received: 01 October 2015; accepted: 19 November 2015)

\begin{abstract}
The article describes the trends of the development of Kalmyk nomadic economy in the late XIX - early XX centuries. Based on the degree of the scrutiny of the problem, the authors have implemented the following tasks: they described the changes in the development of Kalmyk nomadic economy, revealed their causes and analyzed their consequences. The article is based on the use of a large range of literature and sources, many of them are archival materials. The most important among them are the materials of annual reports of the Administration of the Kalmyk people of the Astrakhan province and the chief police officer of nomadic peoples of the Stavropol province. In some cases, the authors used observations and notes of the researchers, contemporaries of the described events. An analysis of the specific material revealed that in the late XIX - early XX centuries the most significant changes related to the transition to a settled way of life and to market conditions occurred in nomadic Kalmyk economy in the process of integration of the region into all-Russian market. During the period under study the number of animals increased, species content of the herds changed (there was an increase in the number of cattle and fine-wool sheep and stabilization of the number of camels and Kalmyk breed sheep). Kalmyk population was engaged in laying in fodder for the winter, breeding animals, building reservoirs for livestock. In some areas of Kalmykia, an intensive transition to agriculture took place.
\end{abstract}

Key words: Nomadic farming, animal husbandry, Kalmyk ulus, marketability, economic regionalization, intensification, breeding.

Modernity exposed many crises in the agricultural development of Kalmykia. That crisis was in the decline in production, a slow transition from a controlled production to the market, which caused a lot of problems, in lowering the standard of living of the rural population. As a consequence of market reallocation of labor there was a significant outflow of the population from the countryside to the city. One reason among many that led to this result is the neglect of the historical experience. In the process of formation and

\footnotetext{
* To whom all correspondence should be addressed.
}

development of the planned Soviet economy there was a drastic change in the economic structure of Kalmykia (the share of crop production increased unreasonably, animal husbandry became sedentary, that was followed by some significant negative changes). This led to the desertification of the large part of Kalmykia.

The urgency of the problem under consideration is to find the optimal model of economic development of the arid areas, and therefore it is important to determine its orientation. In our opinion, in the late XIX - early XX centuries favorable conditions for dynamic development of the region were created: the demographic structure, the market redistribution of the population, the ratio of economic activities and economic regionalization. 
Based on the degree of the scrutiny of the problem, the authors of the article set the following tasks: to describe the changes in the development of Kalmyk nomadic economy, to reveal their causes and to analyze their consequences.

\section{METHOD}

The stated problem has a rich historiography. By the end of the XIX century contemporaries described the technology of nomadic animal husbandry. However, some authors considered nomadic housekeeping as disorderly wandering in the steppe, and the Kalmyk herdsmen were described as "apathetic, lazy and careless" and "not resourceful" in difficult circumstances (Dubrova, 1988). Expert in ethnography and history of the Kalmyks I. Zhitetsky considered Kalmyk nomadic economy as ordered and clearly demarcated in nomads' camps production with summer and winter pastures (Zhitetsky, 1892). N. Ochirov published a book on the economic history of the Kalmyks (Ochirov, 1925), where he described some innovations in Kalmyk agriculture. He considered the signs of transition to a settled way of life, the development of agriculture, gardening, horticulture and melon growing to be the changes of this kind. In 1920s N.Palmov and A. Lebedinsky paid attention to some elements of the Kalmyk economy (Palmov, 1925; Lebedinsky, 1925-1926). The first scholar described the development of animal husbandry of the Kalmyks, focusing on the quantitative indicators of the industry. The latter provided some information about the changes in the local economy (the transition to a settled way of life, the development of agriculture) in the general essay on the state of the Bolshederbetovsky ulus of the Stavropol province.

Then there was the phase of the Stalinist reforms and the Second World War, during which the Kalmyk people was subjected to forced deportation to the eastern regions of the USSR and the Kalmyk State was eliminated. That tragic event caused oblivion of Kalmyk history and the backlog of scientific thought of Kalmykia for 30 years or more. After the rehabilitation of the Kalmyks and their return home, the restoration of national statehood in the form of an autonomous republic the first generalizing work on the history was published (Essays, 1967), in which the authors of the relevant sections payed special attention to the reform of 1892 abolishing personal dependence of Kalmyk commoners on the nobility (noyons and zaisangs). Besides, some elements of the Kalmyk economy are described in that work. In our view, this generalizing work has defined the initial level of the Kalmyk historical science. In 1970 - 1980s the work of U. Erdniev was published (later republished three times) in which the author gave an ethnographic description of the agriculture activities of the Kalmyks (Erdniev, 1970, 1980, 1985). In 1989 L. Burchinova and A. Komandzhaev presented economic history of Kalmykia in the second half of XIX - early XX centuries in their work (Burchinova, Komandzhaev, 1989). In the modern period, the work by A. Komandzhaev was published (Komandzhaev, 1999), in which the author analyzed the development of the Kalmyk economy and social relations in the period under consideration, besides, "History of Kalmykia from ancient times to the present day" in 3 volumes was prepared (History, 2009). The publication of historical and economic work of L. Badmakhalgaev became a notable phenomenon (Badmakhalgaev, 2003).

In the English-language historiography there are no special works devoted to this problem. Some works were published, which touch on the general questions of history of nomadism and are of great theoretical and methodological interest for us (Bold, 1996; Martin. 2010; Vasjutin, 2003; Kradin, 2008; Zhang, Borjigin, Zhang, 2007; Humphrey, 1978). There are a large number of published statistical and legislative sources on the economic history of Kalmykia of this period, among which we should highlight the materials of the First national population census of the Russian Empire of 1897 (the First, 1899-1904), the military-horse censuses of 1901 and 1912 (Military-horse, 1902, 1914), a survey of the Kalmyk steppe of 1909 (Proceedings, 1910). The archival materials, in particular, the annual reports of the Office of the Kalmyk people have a special place in the study of the issue. In some cases, the authors used these reports to calculate averaged numerical values of the Kalmyk economy. 
RESULTS

Based on statistical data and the study the authors drew a conclusion of a significant quantitative growth of livestock in Kalmykia in the late XIX - early XX centuries. However, this increase is observed in fine-wool sheep breeding and cattle breeding. The number of camels and sheep of the Kalmyk breed remained at the same level on the whole. In this connection, changes began to occur in the specific structure of the Kalmyk animal husbandry. Such structural changes became quite a complex phenomenon in some encampments of Kalmykia. Sources also indicate the increased transition of nomadic Kalmyk population to a settled way of life. The transition to a settled way of life is supported by the digital data on the number of stationary structures in the Kalmyk encampments, laying in winter fodder reserves for livestock. In some areas the population is characterized by the transition to the agriculture. We should note the sustained economic regionalization characteristic of this period: central uluses of Kalmykia remained pastoral areas, the residents of the south-west and north of the region became agricultural and pastoral population, the main occupation in the Caspian part was fishin. Also, there are cases of systematic selection of animals as a sign of the intensification of livestock farming.

Table 1. Livestock sector of the Kalmyk steppe in the Astrakhan province (1892-1916). The average annual rate (th. heads)

\begin{tabular}{lcccccc}
\hline Years & Horses & Cattle & Sheep & Goats & Camels & Pigs \\
\hline $1892-1896$ & 64,0 & 114,4 & 557,4 & 10,2 & 16,6 & 0,9 \\
$1897-1901$ & 64,5 & 117,7 & 352,5 & 13,6 & 20,0 & 0,5 \\
$1902-1906$ & 79,5 & 196,1 & 615,8 & 27,0 & 27,2 & 0,5 \\
$1907-1911$ & 66,7 & 153,1 & 573,4 & & 23,6 & 0,3 \\
$1912-1916$ & 74,3 & 188,9 & 686,1 & 16,2 & 20,7 & 0,4 \\
\hline
\end{tabular}

The average values are derived by the authors from the materials of the annual reports of the Administration of the Kalmyk people of the Astrakhan province

Table 2. Livestock sector in Bolshederbetovsky Ulus of the Stavropol province (1901 - 1913). The average annual rate (th. heads)

\begin{tabular}{lcccccc}
\hline Years & Horses & Cattle & Sheep & Goats & Camels & Pigs \\
\hline $1901-1905$ & 3,7 & 37,7 & 110,7 & 1,4 & 1,2 & 0,2 \\
$1906-1910$ & 3,2 & 25,9 & 32,7 & 0,7 & 0,9 & 0,09 \\
$1911-1913$ & 4,0 & 30,4 & 65,0 & 1,1 & 1,9 & 0,1 \\
\hline
\end{tabular}

The average values are derived by the authors from the materials of the annual reports of the Administration of the Kalmyk people of the Astrakhan province.

\section{DISCUSSION}

General quantitative indicators of Kalmyk animal husbandry

New developments in the economy of Kalmykia influenced primarily animal husbandry, the main traditional branch of Kalmyk economy. The general data of the size of livestock sector in Kalmyk uluses in the Astrakhan province in the late XIX - early XX centuries are shown in Table 1.

Overall the growth in the number of Kalmyk herds in that period is noticeable. The number of horses has increased by $23 \%$ on average, the number of cattle - by $69 \%$, sheep by $50 \%$. These figures, of course, indicate the impact that the all-Russian market had on the general condition of livestock sector in Kalmyk encampments.

Another indicator demonstrates the same. If in the last decade of the XIX century there were 47 horses, 88 head of cattle, 336 sheep on average per 100 people in Kalmyk encampments, in the subsequent period, these figures have increased considerably and there were 58 horses, 146 head 
of cattle and 508 sheep on average.

The total livestock (see Table 2) even decreased in Bolshederbetovsky Ulus of the Stavropol province in the first decade of the XX century, the main reason being the preferential development of agricultural production and the growth of the agricultural population at the expense of the cattle-breeding one.

The above figures characterize the livestock sector of the Kalmyk population of the Astrakhan and Stavropol provinces only. In view of the livestock sector of migratory (RussianUkrainian) peasant population, quantitative dynamics of the total livestock in Kalmykia is as follow: the number of horses has increased up to 88 thous. heads, the number of cattle has also increased to 455 ths., the number of sheep has increased to 1500 thousand. The increase in livestock population in Kalmykia is associated with the involvement of the region in the national market.

Specific structure of the Kalmyk livestock sector

Growth in the number of horses was caused by extreme need to replenish the Russian cavalry with Kalmyk saddle horses. According to statistics, 6 - 7 thousand head of Kalmyk horses were supplied to the market annually, their number reached 10 thousand in 1914. (Estimated by the authors on the materials of annual reports of the Administration of the Kalmyk people). There were quite a few large horse breeders in the Kalmyk steppe having several hundred or even several thousand horses in their herds. In 1899, 104 people ( $0.5 \%$ of all owners) concentrated $53 \%$ of the horses in the Kalmyk encampments, of which more than half was the share of 17 individuals who each had more than 500 horses (National Archives of the Republic of Kalmykia, fund 9, inventory 4, file 1109, sheets 6-128). The same situation was observed in the subsequent years. In 1906, 0.5\% hosts in the Kalmyk steppe had $52 \%$ of the total population of horses. Of these, $40 \%$ belonged to only 9 individuals (Russian State Historical Archives, fund 1291 , inventory 84 , file 84 , sheets $68-88$ ). The military-horse census of 1912 revealed that only $40.2 \%$ of households had horses, others were horseless. $0.6 \%$ of households concentrated 58.6\% of the total number of horses. It should be noted that the total number of horses in the Kalmyk encampments of the Astrakhan province increased by $10 \%$, from 66.2 to 72.8 thous. heads over 6 years (1906-1912.).

We can also point to the fact that in 1912 there were 35 residents of the Kalmyk steppe per 115 owners in 50 provinces of European Russia, each having more than 300 horses: 34 Kalmyks and one peasant settler. (Military-horse, 1914, pp. 263-267). There was a large proportion of nonworking-age horses in Kalmykia. Thus, militaryhorse census of 1901 fixed in the Kalmyk steppe the lowest percentage of working age horses - 52.3 in the surveyed localities of European Russia, while in other regions, they constituted the overwhelming majority, for example, in Moscow and Petersburg provinces, 83.2 and $90.4 \%$ respectively. In our opinion, it could be explained by the fact that Kalmykia was the region suppling horses, and secondly, mostly large commercial farms were typical of horse breeding here. This is evident from the fact that in the Kalmyk steppe of the Astrakhan province 8 horses was the share of one breeder, while in the European part of Russia the share ranged from 1.4 to 4 horses. It is natural that management of large stud farms required planned reproduction of the herd from the owners, that is why the ratio of the number of working-age and nonworking-age horses was approximately equal.

Probably the expressive picture would be even more vivid if we could compare the data over a long period. Unfortunately, data on the horse breeding appeared in the records of the Administration of the Kalmyk people only from the mid-1890s, at the same time we have far from all the information and only on certain districts at our disposal. Complete data, offering the possibility of summing over all uluses of the Kalmyk steppe, are presented only for 1899 and 1908.

The population of the Kalmyk cattle breed also increased due to the high meat conditions and market demand. This breed is widespread in Kazakhstan, southern Russia and Ukraine. Kalmyk sheep breeding developed in two directions in that period: on the one hand, the number of Kalmyk breed sheep remained at the same level as those sheep belonging to a meat breed had rough wool suitable only for the manufacture of felt, felt mats and others. On the other hand, there was a rapid increase in the number of fine-wool sheep in Kalmykia as the textile industry of the Russian Empire was badly in need of that wool. Ñamel 
population remained at the same level in the period under consideration (20-24 ths. heads). This was due to the lack of a broad market demand for this type of animal and the scope of their application only in the household. Thus, there have been some changes in the structure of the Kalmyk livestock sector.

In the late XIX - early XX centuries the specificity of area-specific structure of the Kalmyk livestock sector was established. Residents of the northern part of Kalmykia were the largest producers of cattle: this area concentrated more than $55 \%$ of the total stock of these animals in the Kalmyk encampments of the Astrakhan province. Also there was more than $41 \%$ of the total sheep population here (estimated by the authors of the reports of the Administration of the Kalmyk people).

The most striking changes in the structure of livestock sector occurred in the south-west of Kalmykia (Bolshederbetovsky Ulus of the Stavropol province): traditional nomadic economy sectors (horse breeding and camel breeding) decreased to low levels ( $4.0 \%$ and $0.1 \%$ of the total number of animals respectively); Kalmyk sheep breeding was virtually replaced by fine-wool sheep breeding; the number of cattle increased steadily. Such a change in the structure of livestock sector was caused by the transition of the Kalmyks of Bolshederbetovsky ulus to a settled way of life.

Transition of the Kalmyk population to a settled way of life

Significant changes also occurred in trade. Cattle, horses, sheep, fine-woo were in the greatest demand, which determined their quantitative growth. The scale of commercialization of these industries were expressed in annual sales of more than 6-7 thousand horses, about 26 thousand head of livestock, about 65 thousand head of sheep. The sale of camels remained on the same level.

In the period under study there were uncontrolled prices for Kalmyk animals: the average price of a horse was 175 rubles, a head of cattle - 30 rubles, a sheep - 3.5 rubles. According to the survey of 1909, the most profitable livestock industry in Kalmykia was horse breeding: net income from keeping a horse was 13 rubles. Profit from keeping a cow was 11 rubles, a sheep - 3 rubles, a camel -5 rubles.
Among the new phenomena in the development of Kalmyk nomadic economy is a dynamic process of transition to a settled way of life. Even earlier there were significant restrictions on migrations of the Kalmyks, from the end of XIX century interulus transitions became rare, interulus and even interaimakh migrations were limited in a number of Kalmyk societies ("ulus" is a land ownership of noyons, high Kalmyk nobility; "aimakh" is a land ownership of zaisangs, smaller representatives of nobility). Those restrictions were linked to an ongoing process of withdrawal of land from the Kalmyks in favor of Russian and Ukrainian peasant settlers, reduction of pastures due to plowing land for crop production, as well as the growth of the livestock population.

Transition of the Kalmyk population to a settled way of life is noticeable mostly due to the increase in the number of stationary structures (houses, barns, livestock buildings): during the period under study their number increased to 19.5 thousand in Kalmyk encampments of the Astrakhan province, including about 5 thousand wood and wattle and daub houses. Transition of the residents of Bolshederbetovsky ulus of the Stavropol province to a settled way of life was even more extensive: more than 6.2 thousand stationary buildings here were the share of two thousand families. It can be noted that in this part of Kalmykia transition to a settled way of life was completed. Another indicator of the transition to a settled way of life is winter fodder supplies for livestock. According to the survey of 1909, the amount of hay, straw, reed stocked annually in the Kalmyk steppe of the Astrakhan province was enough to feed $25 \%$ of the population of the Kalmyk cattle. The haying volume was much higher in the northern encampments of Kalmykia, in places with more favorable soil and climatic conditions. In general, we can conclude that the transition to a settled way of life took place in the south-west and north of Kalmykia to a greater extent. But we should not exaggerate the extent of this process, since the winter migrations of cattle of all the Kalmyk uluses during the shortage of fodder in the snowless Black lands took place until the middle of the XX century.

Lack of hayfields was explained by soil and climatic conditions as well. In 1902, P. Zubovich, an inspector of the Fish and seal 
fisheries administration expressed his excitement over a large area of sand of 375 thousand dessiatinas (Proceedings, 1903, p.26) which constituted over $60 \%$ of inconvenient land in the Kalmyk steppe.

It is natural that exhaustion of soil as a result of predatory extensive forms of its usage put the fight with sand conducted by various means on the agenda. In 1902 plowing the land in Yandyko-Mochazhniy Ulus was banned for 3 years 'in order to avoid increasing the sands'; the congress of the ulus Trustees and Kalmyk herdsmen in 1907 resolved to partially consolidate the shifting sand areas by grass using public funds under the supervision of specialists. Since 1906 there has been some noticeable increase in sand area planted with grass (Averyanov, 1912, p.15):

Years Planted (dessiatinas) \% compared to 1906. $1906 \quad 60,0 \quad 100$

$1907 \quad 170,0 \quad 283,3$

$1908 \quad 2075,72 \quad 34,6$ times

$1909 \quad 6637,01 \quad 110,6$ times

$1910 \quad 7426,20 \quad 123,8$ times

There were cases of grass cultivation on bad ground by some rich cattlemen, for example, B. Kenzeev. Although the results of such activities were small (about $5 \%$ of sand only was planted over 6 years), but these facts are of interest first and foremost as an attempt to intensive land use.

There is another very important social factor that influences its development. In particular, in 1913, according to the reported data, $18 \%$ of households in the Kalmyk steppe did not have cattle and thus were forced to switch to a settled way of life due to unfavorable circumstances. One should also take into account the poor people who had a small number of livestock. Due to poverty, those hosts were unable to build any structures, they huddled in dzholums (yurt made of poles and felt), and, of course, the official reports on the number of buildings can not reflect the full extent of the development of Kalmyk settled way of life.

\section{Water supply and animal breeding}

A new phenomenon in the Kalmyk nomadic economy is elements of intensification which were expressed not only in haying, construction of stationary buildings, but in drylands irrigation as well. Wells, dams for collecting water were established in the Kalmyk encampments every year (according to the reported data, 33 wells with log cabins, 522 wells without log cabins and 25 dams for reservoirs were built in 1899). Unfortunately, the minimum level of fresh water was available only in Ergeninskaya part of Kalmykia, while in the eastern encampments there was shortage of fresh water. That is why people of this part of Kalmykia often consumed salt water using highly mineralized water for domestic needs. In the period under study large cattle owners of the eastern regions of Kalmykia were engaged in constructing artesian wells up to 200 meters deep. D.Karuev, G.Dalanov and M.Erdeniev possessed such kind of wells.

Among the indicators of the intensification of nomadic economy is certainly breeding animals. This clearly revealed itself in the Kalmyk horse breeding. The largest breeders of Kalmykia improved breed qualities by crossing Kalmyk breed horses with Arab and Don lines. According to the military-horse censuses of 1891, 1901 and 1912 Kalmyk horses were registered by military department as a source of replenishing the cavalry due to high breed qualities. Kalmyk breed cattle was among high-breed lines. Exhibition samples of Kalmyk breed calves reached a weight of $800 \mathrm{~kg}$ or more. High meat conditions were among high-breed qualities of Kalmyk cattle. Therefore, the cattle of Kalmyk breed was sold in all the markets of Central Asia, Kazakhstan, southern Russia and Ukraine. In recognition of the high quality Kalmyk breed sheep (weighing over $60 \mathrm{~kg}$ ) were sold to "El Paso" nursery in America.

Kalmyk economic regionalization in late XIX - early XX centuries deserves attention. Analysis of the available data leads to the conclusion that in that period the uluses of central part were purely pastoral, the northern and southwestern parts of Kalmykia became pastoralagricultural areas. At the same time, prevailing industry of Bolshederbetovsky Ulus was agriculture: according to the report of the chief police officer of nomadic peoples of the Stavropol province, profits from selling bread exceeded that from selling cattle almost by 20\%. In the part of the Caspian Sea (Yandyko-Mochazhniy ulus) residents of the steppe zone were cattle-breeders, while residents of coastal areas were engaged in fishing. The same economic structure was characteristic of Hosheutovskiy Ulus located on the both banks of the Volga River. 


\section{CONCLUSION}

Thus, the analysis of the sources at our disposal gives an indication of major changes in the development of Kalmyk nomadic economy in the late XIX - early XX centuries. Influenced by the all-Russian market there was a significant quantitative growth in livestock in Kalmyk encampments due to fine-wool sheep and cattle, while the number of horses and Kalmyk breed sheep stabilized, except for a few years. The specific structure of the Kalmyk livestock sector with its area-based features changed to some extent. There was an intensive transition of Kalmyk nomadic population to a settled way of life, expressed in stocking winter fodder supplies for cattle, constructing stationary buildings. This process was most noticeable in the encampments with favorable soil and climatic conditions. It is also important to mention the social factor of the process, when the impoverished sections of the population were forced to transit to a settled way of life. There were elements of the intensification of farming, expressed in animal breeding, organization of reservoirs, wells.

\section{ACKNOWLEDGEMENTS}

This article was prepared within the framework of the state task of the Russian Education and Science Ministry "Nomadic society and economy of the Kalmyks in the late XVIII early XX centuries: problems of integration into the Russian national system" (KalmSU, project code number 2641).

\section{REFERENCES}

1. Bold, B. O., Socio-economic segmentation-” Khot-Ail” in nomadic livestock keeping of Mongolia. Nomadic Peoples, 1996.

2. Humphrey, C., Pastoral nomadism in Mongolia: The role of herdsmen's cooperatives in the national economy. Development and Change, 1978; 9(1): 133-160.

3. Kradin, N. N., Early state theory and the evolution of pastoral nomads. Social Evolution and History, 2008; 7(1): 107-130.

4. Martin, V., Kazakh Chinggisids, land and political power in the nineteenth century: a case study of Syrymbet. Central Asian Survey, 2010;
29(1): 79-102.

5. Vasjutin, S. A., Typology of pre-states and statehood systems of nomads. Nomadic Pathways in Social Evolution, 2003; 50-62.

6. Zhang, M. D. A., Borjigin E. \& Zhang, H., Mongolian nomadic culture and ecological culture: On the ecological reconstruction in the agro-pastoral mosaic zone in Northern China. Ecological Economics, 2007; 62(1): 19-26.

7. Averyanov, A.A., Summary Report of work on strengthening the sands in the Kalmyk steppe. Astrakhan, 1912.

8. Badmakhalgaev, L. Ts., Economy of Kalmykia: the evolution and potential of sustainable development. Elista: Dzhangar Publishers, 2003.

9. Burchinova, L.S. \& Komandzhaev, A.N., From feudalism to capitalism: the history of economic development of the pre-revolutionary Kalmykia. Elista, 1989.

10. Military-horse census of 1899-1901. Statistics of the Russian Empire. T. 55. SPb.: 1902; 228.

11. Military-horse census of 1899-1901. Statistics of the Russian Empire. T. 83. SPb.: 1914; 441.

12. Dubrova, J.P., Way of life of the Kalmyks from Stavropol province. 2nd edition. Elista, 1988.

13. Zhitetsky, I.A. (1892). Astrakhan Kalmyks (observations and notes). Astrakhan

14. History of Kalmykia from ancient times to the present day: in three volumes. - Elista, Gerel Publishers, 2009.

15. Komandzhaev, A.N., Economy and social relations in the Republic of Kalmykia in the late XIX - early XX centuries: the historical experience and the present. Elista: Dzhangar Publishers, 1999.

16. Lebedinsky, A.A., Bolshederbetovsky ulus in the second half of the nineteenth century. Kalmyk region, 1925; 2-3, 1.

17. Statistical materials and economic and naturalhistorical study of the Kalmyk steppe of the Astrakhan province. In 2 parts. Astrakhan: 1910 - 1014.

18. National Archives of the Republic of Kalmykia, fund 9, inventory 4, file 1109.

19. Studies in the History of the Kalmyk ASSR. Pre-October period. M.: Nauka, 1967.

20. Ochirov, N.O., Astrakhan Kalmyks and their economic condition in 1915. Astrakhan, 1925.

21. Palmov, N.N., Animal husbandry in the Kalmyk steppe. Kalmyk region, 1925; 1 : 101-117.

22. The first national census of the Russian Empire of 1897. II, Astrakhan Province. 1-2 Notebooks. SPb.: 1899-1904.

23. Russian State Historical Archives, fund 1291, inventory 84. 
24. Proceedings of the local committees on the needs of agricultural industry. II. Astrakhan Province. SPb.: 1903; 336.
25. Erdniev, U.E. The Kalmyks (historical and ethnographic essays). 1-3 editions. Elista: 1970, 1980, 1985. 